\title{
Remote Sensing of Phragmites australis Invasion in Delaware Tidal Marsh Zones: Issues to Consider
}

\author{
Gulnihal Ozbay ${ }^{1 *}$, Andrew Augustine ${ }^{1}$ and Reginald Fletcher ${ }^{2}$ \\ ${ }^{1}$ Department of Agriculture and Natural Resources, Delaware State University, Dover, DE, USA \\ ${ }^{2}$ USDA Agricultural Research Service, Stoneville, MS, USA
}

Phragmites australis, the common reed, has been widespread in tidal marshes of the eastern coast of North America during the last 50 years [1-3]. Its ability to supplant other wetland vegetation and decrease wetland biodiversity has attracted considerable research attention in the U.S. It is estimated that about 10-15 percent of Delaware's coastal wetlands are now invaded with tall, dense stands of $P$. australis $[4,5]$. Monitoring potential impacts of Phragmites invasion on aquatic species such as the blue crab population in Blackbird Creek watershed, Delaware can greatly help understand the changing ecosystems in Delaware's coastal environment. This arduous and complex task can be accomplished utilizing remote sensing technology.

Numerous studies have shown that $P$. australis invasions negatively impact essential fish habitats [6-8]. Currently, it is not clear how invertebrates have responded to $P$. australis invasions. Research by Jivoff and Able [9] suggest marsh surface vegetation influences the way blue crabs use marsh surface habitats. In the state of Delaware, $P$. australis is extensively studied, but most of these studies focus on the mechanism and prevention of Phragmites' invasion [10,11]. Very few studies involved the detection and mapping of $P$. australis and its impact on fishery habitat in Delaware (Figure 1).

Remote sensing techniques present a means to detect, map, and monitor Phragmites with varying degrees of success. In early 80 s, Ihse and Graneli [12] identified the relationship between Phragmites live shoot biomass and the infrared/red reflectance ratio using a hand-held digital instrument. Color aerial photos with high spatial resolution have shown potential as a tool for mapping $P$. australis $[13,14]$ with acceptable accuracy. Bailey [15] conducted a remote sensing study on the extent of $P$. australis in Blackbird Creek Watershed, Delaware using color infrared aerial photography. Results indicated that total coverage of Phragmites in Blackbird Creek increased from 371.18 hectares, $26.5 \%$ of the study area in 1979 to 634.96 hectares, $45.4 \%$ of the study area in 1993.

Recording the presence of $P$. australis within a tidal marsh zone presents quite a challenge in terms of the physical execution of a vegetation survey in an environment with restricted mobility, the overall study region with an area measurement on the order of tens

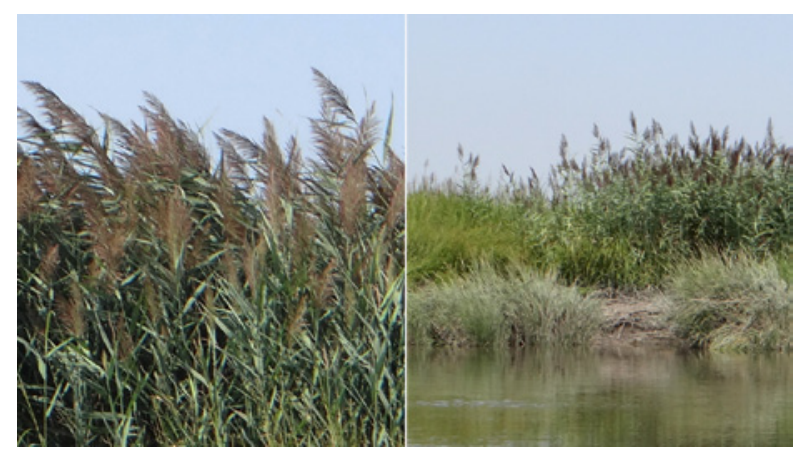

Figure 1: Phragmites australis (left) and $P$. australis in mixed vegetation stand (right). to hundreds or even thousands of square kilometers, as well as the accuracy of species identification via sensor capabilities and various classification methodology. Remote sensing utilizing satellite or aerial imagery enables one to more easily collect data from afar without having to physically be present in the harsh environment. Additionally, remotely-sensed imagery can be collected at various resolutions providing detail on a multitude of scales. Lastly, various algorithms and sensor capabilities provide varying degrees of accuracy for species identification (Figure 2).

An important factor in the classification or monitoring of a wetland species such as $P$. australis utilizing remotely-sensed data involves the concept of scale. Particularly, the extent of an intended study area has a great impact on the necessary available data to analyze. A sensor with high spatial resolution will be able to provide finer detail compared to a medium resolution sensor over the same geographic area. If a particular study area has a large geographic extent, the use of satellite imagery with a coarse resolution $(10-30 \mathrm{~m})$, such as Landsat Thematic Mapper (TM) or Le Systeme Pour l'Observation de la Terre (SPOT), may be sufficient. However, if the primary interest is on the order of several hundred meters or a few kilometers in lineal extent, perhaps aerial photography or the use of high-resolution (1-4m) imagery, such as IKONOS or QuickBird, may be more appropriate or beneficial. The

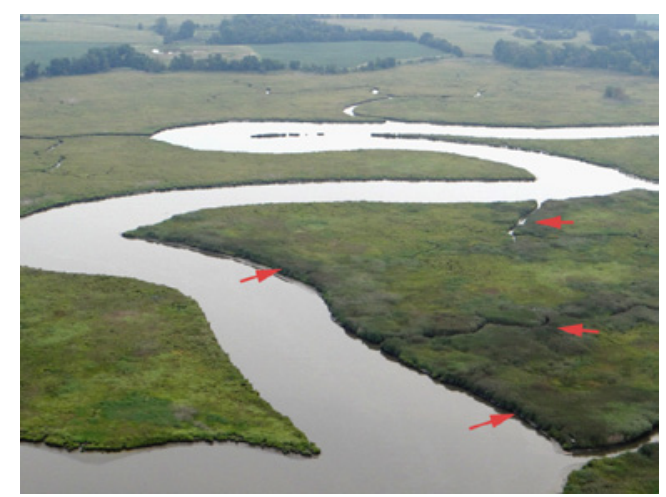

Figure 2: Flyover photo taken in August 2012 over Blackbird Creek Watershed, Delaware. Arrows indicate presence of $P$. australis.

*Corresponding author: Gulnihal Ozbay, Department of Agriculture and Natural Resources, Delaware State University, Dover, DE, USA, E-mail: gozbay@desu.edu

Received September 10, 2012; Accepted November 07, 2012; Published November 16, 2012

Citation: Ozbay G, Augustine A, Fletcher R (2012) Remote Sensing of Phragmites australis Invasion in Delaware Tidal Marsh Zones: Issues to Consider. J Geophys Remote Sensing 1:e107. doi:10.4172/2169-0049.1000e107

Copyright: (C) 2012 Ozbay G, et al. This is an open-access article distributed under the terms of the Creative Commons Attribution License, which permits unrestricted use, distribution, and reproduction in any medium, provided the original author and source are credited. 
use of imagery with high spatial resolution may not necessarily result in improved detection or classification accuracy.

Generally speaking, multispectral data is useful for determining broad vegetation classes and hyperspectral data is effective for differentiating vegetation classes at the species level. Although it is noted that high-resolution imagery or hyperspectral data may lose effectiveness due to different vegetation species having similar biochemical and biophysical properties [16]. Additionally, results may suffer due to spectral variations in the same species as a result of issues such as age differences, soil and water background, or stresses most notably in the near-to mid-infrared bands.

Classification of various wetland vegetation species including $P$. australis poses a complex challenge utilizing remote sensing techniques. As stated by Shippert [17], standard multispectral image classification techniques are generally developed to classify multispectral images into broad categories while hyperspectral imagery provides an opportunity for more detailed image analysis for specific narrow range. Hyperspectral data derived vegetation classifications generally are possible due to the ability to distinguish species using known reference spectra or spectral libraries.

However, high-resolution imagery can have difficulty in resolving spectral variance within-class; sometimes pixel-based classification techniques are replaced with object-based methods such as "Region growing" [18]. Another method for classification known as linear unmixing [19] can be employed for sub-pixel analysis when a pixel is determined to be mixed vegetation [20].

The combination of radar and optical data provide promise for improved wetland classification [21]. The use of Light Detection and Ranging (LiDAR) has been noted to be helpful in separating the higher reed P. australis from lower marsh plants [22]. Improved classification results have been achieved utilizing ancillary data (e.g., aerial photos, soils data, field samples, elevation data, etc.) or rule-based expert systems [23]. Even so, there is still no agreed upon method that successfully distinguishes $P$. australis with very high accuracy. Some additional considerations in conducting research associated with detection and monitoring of vegetative species such as $P$. australis include the concept of periodicity or time, cost, and complexity of processing or usability.

Temporal resolution or how often a sensor revisits an area should be considered when determining presence and abundance of a wetland vegetation species such as $\mathrm{P}$. australis. This point is even more relevant when conducting a change detection analysis. Furthermore, change detection of satellite imagery between different dates is complicated by the fact that the imagery used in any analysis typically requires preprocessing. Two primary components of the preprocessing stage include registration of multidate images and their radiometric rectification involving aspects such as variations in solar illumination and atmospheric scattering and absorption [18].

Environmental processes varying with time pose an obstacle in correctly detecting and classifying tidal wetland vegetation. A formidable challenge in detection and classification methods derives from the changing water level from one point in time to another. As the water level changes, the resulting spectral signature received by the remote sensor becomes mixed [24]. For a species such as P. australis, significant differences in spectral reflectance can also be observed as a result of the time of year based on different phenological stages of development such as in the fall season (Artigas and Pechmann) [20] (Figure 3).

In terms of managing natural resources at fine scales, the cost of field

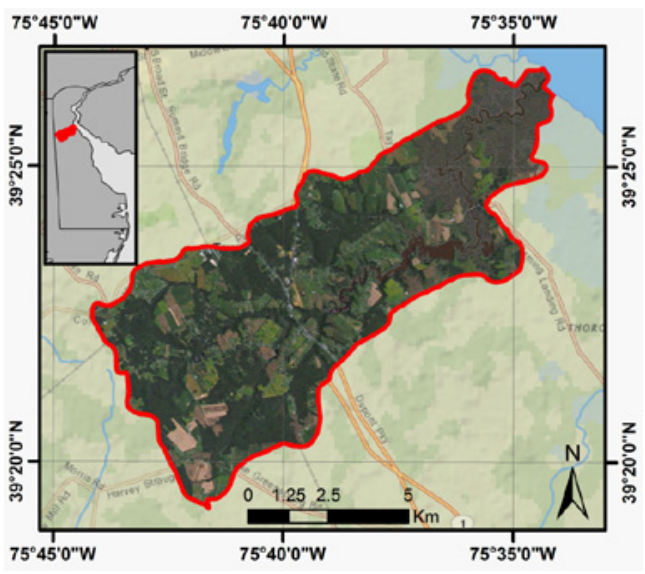

Figure 3: Blackbird Creek Watershed, Delaware.

validation of multi- or hyperspectral imagery is relatively high limiting the use of remote sensing data due to uncertainty of the classifications [20]. A small wetland site may be adequately and reasonably covered with high-resolution satellite imaging. However, as the size of a study site becomes larger, it will likely become more cost-effective to utilize medium-resolution satellite imagery over high-resolution satellite imagery. Whereas aerial photography may be suitable for smaller wetlands or non-frequent observations, mapping or monitoring on a regional scale and increased frequency with such imagery would be costly and time-consuming to process.

Furthermore, the detection and mapping of invasive species such as $P$. australis in tidal wetlands is complicated not only by the complexity of the natural environment. The human element plays a crucial and costly role in the processing, analyzing, and decision making efforts [25]. In a study by National Oceanic and Atmospheric Association completed in 2006, the use of various remote sensing technology involving hyperspectral , medium- and high-resolution multispectral, and aerial imagery was compared. The study included the Blackbird Creek drainage basin. Results indicated the use of aerial hyperspectral imagery to be not user-friendly, complicated for average skilled personnel, and cost-prohibitive for the extent of the study area [26].

Although it is apparent no one method is best for detecting and mapping the extent of $P$. australis in the tidal marsh zones of Delaware, continued research efforts and open communication of results will further broaden the understanding of using various remote sensing technologies in related environments. Investigations of the effects of disturbances on habitat quantity and quality of the Blackbird Creek Watershed via monitoring $P$. australis invasion using satellite remote sensing will provide valuable data to enhance our understanding of the habitat conditions and assess the habitat. Monitoring P. australis invasion and its effect on blue crab abundance, which is an important indicator species in Delaware Bay, expands our knowledge pertaining to the impacts of invasive species on environmentally and economically important aquatic species. Additionally, results will enable decision makers to better conserve and manage coastal marine resources to meet economic, societal, and environmental needs.

\section{References}

1. Orson RA (1999) A paleoecological assessment of Phragmites australis in New England tidal marshes: changes in plant community structure during the last few millennia. Biology Invasions 1: 149-158.

2. Chambers RM, Meyerson LA, Saltonstall K (1999) Expansion of Phragmites 
Citation: Ozbay G, Augustine A, Fletcher R (2012) Remote Sensing of Phragmites australis Invasion in Delaware Tidal Marsh Zones: Issues to Consider. J Geophys Remote Sensing 1:e107. doi:10.4172/2169-0049.1000e107

Page 3 of 3

australis into tidal wetlands of North America. Aquatic Botany 64: 261-273.

3. Warren RS, Fell PE, Grimsby JL, Buch EL, Rilling GC, et al. (2001) Rates, patterns, and impacts of Phragmites australis expansion and effects of Phragmites control on vegetation, macroinvertebrates, and fish within tidal wetlands of the lower Connecticut River. Estuaries 24: 90-107.

4. Natural Resources Conservation Service (NRCS) (2007) Partnering provides assistance for phragmites control in Delaware.

5. Delaware National Estuarine Research Reserve (DENERR) (1999) Estuarine Profile.

6. Able KW, Hagan SM (2000) Effects of common reed (Phragmites australis) invasion on marsh surface macrofauna: response of fishes and decapod crustaceans. Estuaries 23: 633-646.

7. Able KW, Hagan SM (2003) Impact of common reed, Phragmites australis, on essential fish habitat: influence on reproduction, embryological development, and larval abundance of Mummichog (Fundulus heteroclitus). Estuaries 26: 40-50.

8. Hunter KL, Fox DA, Brown LM, Able KW (2006) Responses of resident marsh fishes to stages of Phragmites australis invasion in three mid Atlantic estuaries. Estuaries and Coasts 29: 487-498.

9. Jivoff PR, Able KW (2003) English Title: Blue crab, Callinectes sapidus, response to the invasive common reed, Phragmites australis: abundance, size, sex ratio, and molting frequency. Estuaries 26: 587-595.

10. Seliskar DM, Smart KE, Higashikubo BT, Gallagher JL (2004) Seedling sulfide sensitivity among plant species colonizing Phragmites infested wetlands. Wetlands 24: 426-433.

11. Seliskar DM (2008) Phragmites Control in Delaware: Practical Tips \& Techniques.

12. Ihse M, Graneli W (1985) Estimation of reed (Phragmites australis) biomass through spectral reflectance measurements. Biomass 8: 59-79.

13. Maheu-Giroux M, de Blois S (2005) Mapping the invasive species Phragmites australis in linear wetland corridors. Aquatic Botany 8: 310-320.

14. Philipp KR, Field RT (2005) Phragmites australis expansion in Delaware Bay salt marshes. Ecological engineering 25: 275-292.
15. Bailey AR (1997) Detecting and monitoring Phragmites invasion of coastal wetlands: a comparison of remote sensing techniques. Master's Thesis University of Delaware, College of Marine Studies, Newark, DE USA.

16. Elhadi A, Mutanga O, Rugege D (2010) Multispectral and hyperspectral remote sensing for identification and mapping of wetland vegetation: a review. Wetlands Ecology and Management 18: 281-296.

17. Shippert P (2012) Introduction to Hyperspectral Image Analysis. Research Systems.

18. Klemas V (2011) Remote sensing of wetlands: case studies comparing practical techniques. Journal of Coastal Research 27: 418-427.

19. Settle JJ, Drake NA (1993) Linear mixing and the estimation of ground cover proportions. International Journal of Remote Sensing 14:1159-1177.

20. Artigas F, Pechmann IC (2010) Balloon imagery verification of remotely sensed Phragmites australis expansion in an urban estuary of New Jersey, USA Landscape and Urban Planning 95: 105-112.

21. Ozesmi SL, Bauer ME (2002) Satellite remote sensing of wetlands. Wetlands Ecology and Management 10: 381-402.

22. Yang J, Artigas FJ (2010) Mapping salt marsh vegetation by integrating hyperspectral and LiDAR remote sensing. In: Wang, J. (ed.), Remote Sensing of Coastal Environment. Boca Raton, Florida: CRC Press.

23. Schmidt KS, Skidmore AK, Kloosterman EH, Van Oosten H, Kumar L, et al. (2004) Mapping coastal vegetation using an expert system and hyperspectral imagery. Photogrammetric Engineering and Remote Sensing 70: 703-716.

24. Silvestri S, Marani M, Marani A (2003) Hyperspectral remote sensing of salt marsh vegetation, morphology and soil topography. Physics and Chemistry of the Earth 28:15-25.

25. Vagni F (2007) Survey of Hyperspectral and Multispectral Imaging Technologies. NATO RTO TECHNICAL REPORT TR-SET-065-P3.

26. Porter DE, Field DW, Klemas VV, Jensen JR, Malhotra A, Field RT, et al (2006) RESAAP Final Report: NOAA/NERRS Remote Sensing Applications Assessment Project. Aiken, South Carolina: University of South Carolina. 